\title{
A surprising and dramatic neuroendocrine-immune phenotype of mice deficient in Growth Hormone-Releasing Hormone (GHRH)
}

\author{
K. FAHRAT*, G. BODART*, C. RENARD*, C. DESMET ${ }^{1}$, M. MOUTSCHEN ${ }^{2}$, \\ Y. BEGUIN ${ }^{3}$, F. BARON ${ }^{3}$, R. SALVATORI ${ }^{4}$, V. GEENEN* \& H. MARTENS* \\ *University of Liege, GIGA-I ${ }^{3}$, Laboratory of Immunoendocrinology, Liege, Belgium \\ ${ }^{1}$ University of Liege, GIGA-1 ${ }^{3}$, Laboratory of Cellular and Molecular Immunology, Belgium \\ ${ }^{2}$ Clinical Immunology and Infectiology, University Hospital of Liege, Belgium \\ ${ }^{3}$ University of Liege, GIGA-1 ${ }^{3}$, Laboratory of Hematology, Liege, Belgium \\ ${ }^{4}$ Division of Endocrinology, Johns Hopkins University, Baltimore, USA
}

In the framework of close interactions between the immune and neuroendocrine systems, Growth Hormone $(\mathrm{GH})$ has been proposed to exert significant effects on the immune system, but there is not yet a consensus about GH immunomodulatory properties.

These studies investigated the immune and anti-infectious response of dwarf $\mathrm{Ghrh}^{-/}$mice presenting a severe deficiency of the GHRH/GH/IGF-1 axis.

In basal conditions, thymic parameters and T-cell responses of $\mathrm{Ghrh}^{-1}$ mice were not severely affected but a constant B-cell lymphopaenia was observed. Thus, we investigated vaccine and anti-infectious responses of $\mathrm{Ghrh}^{-1-}$ mice toward Streptococcus pneumonia,

a B-dependent pathogen,

$\mathrm{Ghrh}^{-1-}$ mice were unable to trigger production of specific $\lg \mathrm{M}$ and $\lg \mathrm{G}$ against serotype 1 pneumococcal polysaccharide (PPS) after vaccination with either native PPS (Pnx23) or protein-PPS conjugate (Prev-13) vaccines. These vaccines both include the serotype 1 (our S.pneumoniae strain) and provide an effective protection in mice. A short $\mathrm{GH}$ supplementation to $\mathrm{Ghrh}^{-/-}$mice (1 daily injection of $1 \mathrm{mg} / \mathrm{kg} \mathrm{GH}$ for 4 weeks) restored $\mathrm{lgM}$ and IgG response to Pnx23 vaccine but not to Prev-13. This suggests that GH could exert distinct impacts upon spenic areas.

Furthermore, after intranasal instillation of a non-lethal dose (defined by the full clearance by WT C57BL/6 mice after 24h) of serotype 1 S.pneumoniae, $\mathrm{Ghrh}^{-1-}$ mice exhibited a dramatic susceptibility. This was proved by a marked time-dependent increase in pulmonary bacterial, a septicemia already $24 \mathrm{~h}$ after infection and a survival limit of $72 \mathrm{~h}$. We also observed a dramatic decrease in lung B- and T-cell populations and an increase in proportion of inflammatory macrophages. By contrast, wild-type and heterozygote mice completely cleared S.pneumoniae infection after $24 \mathrm{~h}$.

In conclusion, our data show without ambiguity that the somatotrope GHRH/GH/IGF-1 axis plays an important and unsuspected role in defense against S.Pneumoniae. 